\title{
Surfer's ear in a 29-year-old man
}

\author{
Aidan McParland MSc, Frederique Elffers-Tan MD, Alun Ackery MD MSc
}

Cite as: CMAJ 2019 April 8;191:E396. doi: 10.1503/cmaj.180753

A

29-year-old man presented to an outpatient otolaryngology clinic with a recurrent sensation of fullness and diminished hearing in both ears. The patient had a 20-year history of cold-water surfing and 2 years of frequent ear blockage, especially after surfing. He had experienced several episodes of external otitis, which resolved each time with corticosteroid-antibiotic ear drops. He had no history of persistent hearing loss, tinnitus, vertigo, middle ear infections or previous ear surgeries. Physical examination and otoscopy showed exostoses of the bony external auditory canal bilaterally (Figure 1). Cleaning and suction resulted in partial visibility of the patient's tympanic membranes and normal hearing.

External auditory exostoses, also known as surfer's ear, are benign tumours of the external auditory canal. They form primarily as a result of environmental factors, including recurrent exposure to cold water (below $19^{\circ} \mathrm{C}$ ) or cold air, with a prevalence in surfers ranging from $38 \%$ to $73.5 \% .{ }^{1,2}$ The prevalence and severity of exostoses are dependent on the amount of time spent surfing. ${ }^{2}$ Although exostoses are typically asymptomatic, recurrent otitis externa, hearing loss and a sensation of blockage may be reported in more advanced stages of canal narrowing. ${ }^{3}$ Exostoses are most commonly diagnosed by history and otoscopy. They are sometimes identified by finding conductive hearing loss on audiometry or infrequently on computed tomography. ${ }^{3}$ Histologically, external auditory exostoses are characterized by unilateral or bilateral dense formations of bone originating from the bony external auditory canal. ${ }^{3}$

Initial management of external auditory exostoses should focus on prevention by reducing specific environmental exposures such as cold air or water, through the use of ear plugs, hoods and swim caps. ${ }^{4}$ Frequent canal blockage and otitis externa are common manifestations of external auditory exostoses, which may require microscopic ear cleaning by a specialist and administration of corticosteroid-antibiotic drops, respectively. Surgical intervention is typically suggested only in severe cases of obliterative exostosis, when otitis externa becomes

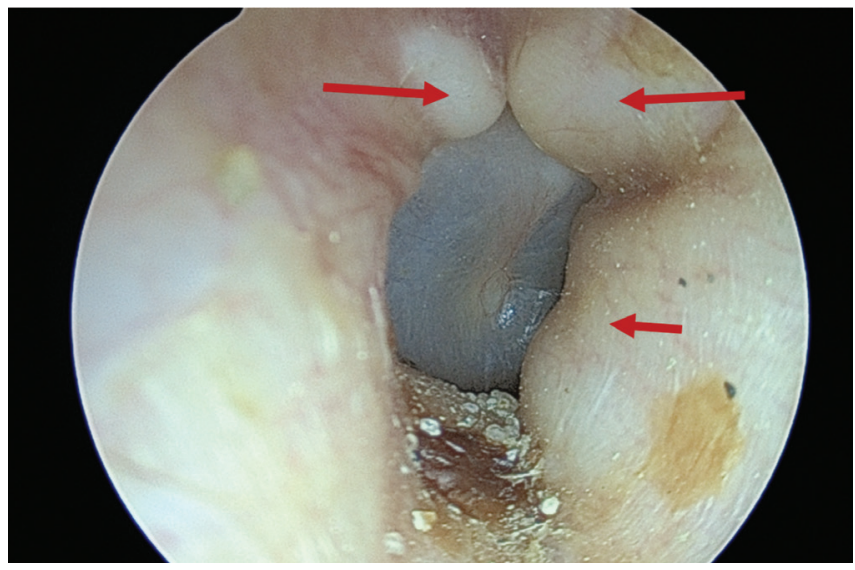

Figure 1: Otoscopic view of the right ear of a 29-year-old man. Superior and inferior exostoses (arrows) are present, with a visible intact tympanic membrane and malleus. Sand and ear wax can be seen on the inferior aspect of the external canal (image obtained using a rigid endoscope $\left[0^{\circ}\right.$, Karl Storz] with Xion Matrix Spectar camera processor).

frequent, or when conductive hearing loss is observed. ${ }^{5}$ Recurrence of exostoses is common after surgery, most frequently with continued exposure to cold water. ${ }^{6}$

\section{References}

1. Kroon DF, Lawson ML, Derkay CS, et al. Surfer's ear: external auditory exostoses are more prevalent in cold water surfers. Otolaryngol Head Neck Surg 2002;126:499-504.

2. Wong BJ, Cervantes W, Doyle KJ, et al. Prevalence of external auditory canal exostoses in surfers. Arch Otolaryngol Head Neck Surg 1999;125:969-72.

3. House JW, Wilkinson EP. External auditory exostoses: evaluation and treatment Otolaryngol Head Neck Surg 2008;138:672-8.

4. DiBartolomeo JR. Exostoses of the external auditory canal. Ann Otol Rhinol Laryngol Suppl 1979;88(Suppl 61):2-20.

5. Fisher EW, McManus TC. Surgery for external auditory canal exostoses and osteomata. J Laryngol Otol 1994;108:106-10.

6. Timofeev I, Notkina N, Smith IM. Exostoses of the external auditory canal: a longterm follow-up study of surgical treatment. Clin Otolaryngol Allied Sci 2004;29:588-94.

\section{Competing interests: None declared.}

This article has been peer reviewed.

The authors have obtained patient consent.
Affiliations: Faculty of Medicine (McParland), University of Toronto, Toronto, Ont.; University Medical Center Utrecht (Elffers-Tan), Utrecht, The Netherlands; Emergency Department (Ackery), St. Michael's Hospital, Toronto, Ont.
Correspondence to: Alun Ackery, ackerya@smh.ca 